\title{
Climate Change and Condition of Herring (Clupea Harengus) Explain Long-Term Trends in Extent of Skipped Reproduction
}

Georg H. Engelhard (g.engelhard@cefas.co.uk)

Mikko Heino (mikko.heino@imr.no)

\section{Approved by}

Ulf Dieckmann

Program Leader, Evolution and Ecology Program

January 2006 


\section{Contents}

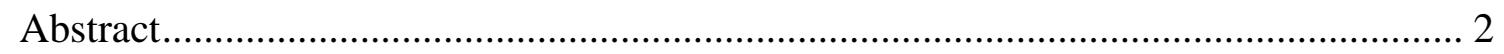

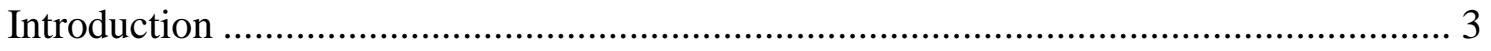

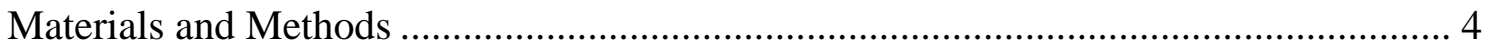

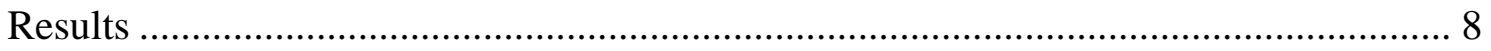

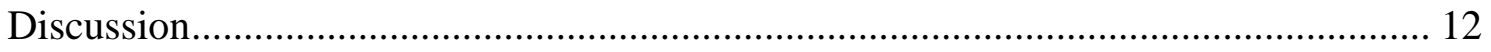

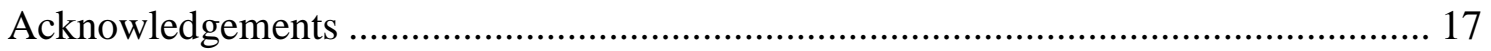

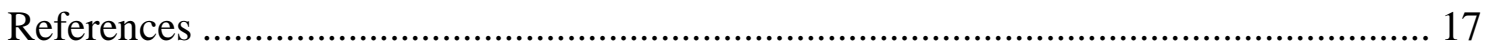

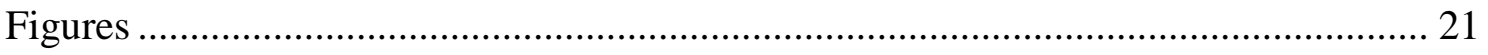

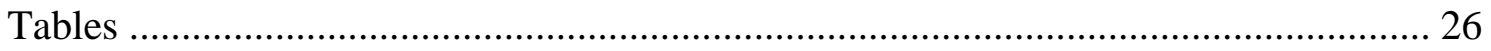




\section{Climate change and condition of herring (Clupea harengus) explain long-term trends in extent of skipped reproduction}

Georg H. Engelhard ${ }^{1,2^{*}}$ and Mikko Heino ${ }^{2,3,4}$

5

${ }^{1}$ Cefas Lowestoft Laboratory, Pakefield Road, Lowestoft NR33 OHT, UK

${ }^{2}$ Institute of Marine Research, P.O. Box 1870 Nordnes, 5817 Bergen, Norway

${ }^{3}$ Adaptive Dynamics Network, International Institute for Applied Systems Analysis, 2361 Laxenburg, Austria

${ }^{4}$ Department of Biology, University of Bergen, P.O. Box 7800, 5020 Bergen, Norway

* Author for correspondence (G.Engelhard@cefas.co.uk; Cefas Lowestoft Laboratory, Pakefield Road, Lowestoft NR33 OHT, UK; tel. +44 1502 527747; fax +44 1502 524546)

Short title Long-term changes in frequency of skipped reproduction 
It is commonly assumed that iteroparous fish, once mature, normally reproduce in all consecutive seasons. Recent work suggested, however, that in Norwegian spring-spawning herring - a population that undertakes extensive spawning migrations-almost one in two adults may skip their second spawning migration. Why should herring not return to spawn the year after first spawning, but instead wait an extra year? This paper describes long-term changes in the extent to which the second reproductive season is skipped in this herring population. These are shown to be linked to the size and condition of herring as first-time spawners, and to climatic factors possibly related to food availability. The findings corroborate the hypothesis that skipped reproduction results from trade-offs between current and future reproduction, growth and survival. For herring, participation in distant, energetically costly, and risky spawning migrations will only pay off in terms of fitness if individuals are sufficiently large, and in sufficient condition, to both successfully migrate and spawn.

Keywords: current and future reproduction; energy stores; environment; skipped spawning season; spawning migration costs and risks 


\section{Introduction}

The reproductive potential and hence future biomass of animal populations are directly influenced by the fraction of individuals involved in reproduction. For iteroparous (i.e. repeatedly reproducing) species, this fraction is not only dependent on growth and maturitytwo aspects that have been widely investigated-but also on the extent to which adult individuals may skip reproductive seasons. Remarkably, the possibility of skipped reproduction has received only relatively little attention in research on fish, including species of high commercial significance (for some notable exceptions, see Rijnsdorp 1990; Oganesyan 1993; Burton et al. 1997; Rideout et al. 2000, 2005; Fiksen and MacKenzie 2001; and Jørgensen et al. 2006). In fact, it is often assumed that adult fish, once matured, normally return to spawn in all consecutive years of life. Recent evidence suggests, however, that skipping of reproductive seasons by adult fish may occur more commonly than usually believed (reviewed by Rideout et al. 2005). For a number of commercially important stocks, there are indications of fairly extensive skipping of reproductive seasons (e.g. Oganesyan 1993; Rideout et al. 2000; Engelhard and Heino 2005).

Norwegian spring-spawning herring, the world's largest stock of Atlantic herring (Clupea harengus), occur in the Norwegian and Barents Seas. In this population, individuals mature at ages of 3-9 years; the maximum life-span is over 20 years. The adult herring undertake long annual migrations between productive summer-feeding areas in the Norwegian Sea, overwintering areas off northwestern Norway, and spawning areas off western and southwestern Norway, where the ripe herring arrive from mid-winter to early spring. Analysis of extensive historical data on scales suggested, however, that individual herring do not necessarily spawn strictly annually (Engelhard and Heino 2005). In samples collected in the spawning areas from 1935-1974, second-time spawners were strongly underrepresented in comparison to both first-time spawners and older repeat spawners. Statistical analysis revealed that on average, about $47 \%$ of potential second-time spawners were apparently absent from the spawning grounds. This suggested that almost one in two first- 
time spawners did not return to spawn the year after, but instead waited an extra year before recommencing reproduction (Engelhard and Heino 2005).

Why should herring not return to spawn the year after first spawning? This paper examines the hypothesis that skipping of reproduction relates to trade-offs between current and future reproduction, growth and survival (Roff 2002). For herring, such trade-offs may imply that participation in distant, energetically costly, and risky spawning migrations will only pay off in terms of fitness if individuals are sufficiently large, and in sufficient condition, to both successfully migrate and spawn. We previously hypothesised (Engelhard and Heino 2005) that first-time spawning herring, due to their small size compared to older, repeat spawners, may often need an extra year to re-gain the energy stores needed to reproduce (Engelhard and Heino 2005). Here we examine the following predictions: (1) that cohort-level variability in size and condition of young adult herring will be mirrored in variations in the extent of skipped reproduction; and (2) that climatic changes related to herring condition will moreover be linked to the extent of skipped reproduction.

\section{Materials and methods}

The data

80 Age, age at maturation (here, age at first spawning), and number of post-maturation years (i.e., years completed since the first spawning event) were obtained from scales of 84116 adult Norwegian spring-spawning herring, sampled randomly in the spawning areas by the Institute of Marine Research (see Engelhard et al. 2003). All samples were collected during January-March of 1935-1973 (see Table 1 for annual sample sizes). Experienced scale readers distinguished between three types of growth layers: relatively wide 'coastal' and 'oceanic' rings, corresponding with the early and late immature stages, respectively; and narrow 'spawning' rings, corresponding with the mature or adult stage (Runnström 1936; Engelhard et al. 2003). For adult herring, the number of coastal and oceanic rings thus equals 
age at maturation, and the number of spawning rings equals the number of post-maturation years. In addition, body length and weight were measured in all samples; an index of body condition was defined as weight length ${ }^{-3}$ (cf. Slotte 1999b).

As a description of interannual environmental variability we used (1) the Kola temperature and (2) the North Atlantic Oscillation (NAO) winter index. The Kola temperature is defined here as the mean annual temperature in the Kola Section of the Barents Sea, averaged over the 0-200 $\mathrm{m}$ depth layer; it is correlated with sea temperatures in the Norwegian Sea (Bochkov 1982). Information on the Kola temperature was extracted from databases of the Institute of Marine Research. The NAO winter index was defined as the December-March average difference of normalised sea level pressure between Lisbon, Portugal, and Stykkisholmur/Reykjavik, Iceland (Hurrell et al. 2003). Information on the NAO index was extracted from http://www.cgd.ucar.edu/cas/jhurrell/indices.html.

Statistical modelling

Modelling survival and skipped reproduction. In this paper, a maturation cohort is defined as all individuals of a year-class sharing the same age at maturation, i.e. that first spawned in the same year (e.g. Beverton et al. 2004). We previously tested the assumption that after maturation, herring return annually to the spawning areas (Engelhard and Heino 2005). This assumption predicts that the numbers of males and females of each maturation cohort, present in the spawning area in consecutive spawning seasons, should solely decrease as a function of mortality. Post-maturation survival was modelled, based on the sampled numbers $(n)$ of fish of a given maturation cohort for each sex, sampled in consecutive years $y$ and $y+1$ and with respectively $p$ and $p+1$ post-maturation years (cf. Fig. 1a). Log-transformation allows using the following linear model: 
where $n_{p, y}$ and $n_{p+1, y+1}$ are the sampled numbers of either males or females of a given maturation cohort with $p$ and $p+1$ post-maturation years, respectively, and $c_{p}$ is a vector of survival coefficients, corresponding to the logarithm of change in numbers from $p$ to $p+1$ post-maturation years. $N_{y}$ and $N_{y+1}$ are the total numbers of fish for all maturation cohorts sampled in the same years (Table 1), included to account for the effects of annual variations in sampling effort on capture probability. $S_{y}$ and $S_{y+1}$ are estimates of the numbers of fish in the spawning stock in years $y$ and $y+1$, respectively, obtained from the official stock assessment (ICES 2002). These were included to account for annual variations in capture probability due to major fluctuations in spawning stock over the period examined (i.e., increase from $\sim 26 \cdot 10^{9}$ spawners in 1935 to $\sim 54 \cdot 10^{9}$ spawners in 1944 , followed by a dramatic decrease to $\sim 9 \cdot 10^{6}$ spawners in 1972).

Survival coefficients $\left(c_{p}\right)$ estimated with model (1) were similar for most transitions, except for the transitions from $0 \rightarrow 1$ and $1 \rightarrow 2$ post-maturation years (Fig. 1b). This suggested constant annual survival and under-representation of fish with 1 post-maturation year in samples. We interpret this as evidence that Norwegian spring-spawning herring frequently skip the second reproductive season (Engelhard and Heino 2005). The extent to which the second spawning season is skipped can be modelled as follows:

where $c_{0}$ is a mean survival coefficient, $c_{1}$ is a coefficient of under-representation in the second spawning season, and $I_{p}$ is an indicator variable with

$I_{p}=1 \quad$ if $p=0$ post-maturation years, and

$I_{p}=-1$ if $p=1$ post-maturation year, and

$I_{p}=0 \quad$ otherwise. 
Mean annual post-maturation survival is thus estimated as $\mathrm{e}^{c_{0}}$, and the fraction of fish

skipping the second spawning season as $1-\mathrm{e}^{c_{1}}$. Note that possible skipped reproduction after the second potential spawning season may confound the survival estimate.

Year-class variability. We examined for year-class variability in the extent to which the second spawning season was skipped by herring, by including year-class $Y$ as a factor in model (1):

150

$\log \left(n_{p+1, y+1, s}\right) \sim \log \left(n_{p, y, s}\right)+\log \left(N_{y+1} / N_{y}\right)+\log \left(S_{y} / S_{y+1}\right)+c_{0, Y}+c_{1, Y} I_{p}$

where $\mathrm{e}^{c_{0, Y}}$ and $1-\mathrm{e}^{c_{1, Y}}$ provide estimates of adult survival and the fraction of fish skipping the second spawning season, respectively, for year-class $Y$. Note that the ratio $S_{y} / S_{y+1}$ is assumed to be accurately known; errors in this ratio will confound the estimates of annual survival and skipped spawning.

Effects of fish size, sex, and environmental variables. We modelled effects of fish sex, size (length or weight), condition, and environmental variables (Kola temperature and NAO winter index) on survival and the extent to which the second spawning season may be skipped. Size and condition were calculated as mean values, by year, for each maturation cohort separately. Model (2) was therefore extended, as follows:

$\log \left(n_{p+1, y+1}\right) \sim \log \left(n_{p, y}\right)+\log \left(N_{y+1} / N_{y}\right)+\log \left(S_{y} / S_{y+1}\right)+c_{0}+c_{1} I_{p}+c_{2} V_{y}+c_{3} I_{p} V_{y}-F$

where the parameters $c_{2}$ and $c_{3}$ describe effects of variable $V$ (size, sex, or environmental variable) on survival and skipped reproduction, respectively. The offset $F$ (fishing mortality [year ${ }^{-1}$ ]: annual averages over ages $2-13$ years; ICES 2002) was added to account for annual losses of fish due to fishing mortality (allowing a focus on how fish size and environmental variables may affect 'natural mortality'). It should be noted that over the study period important changes in fishing mortality took place, remaining low in the 1930s-1940s, 
increasing steadily in the 1950s, and becoming excessively high in the late 1960s-early 1970s (e.g., Toresen and Østvedt 2000). Data for 1966-73, when the spawning stock was virtually fished out and collapsed, were excluded from this part of the analysis. For graphical purposes only, fish size variables were discretisised and analysed as factors. In modelling effects of fish size and environmental variables on skipped reproduction, the transition from $1 \rightarrow 2$ post-maturation years was not included, as it refers to fish returning to spawn after having potentially skipped the second spawning season.

Notice that with the available data, probabilities of survival and skipped reproduction can only be estimated for maturation cohorts. The models used here thus cannot directly reveal how the considered variables affect survival and skipped reproduction at the individual level.

Data selection criteria. The results of the analyses were to a moderate extent affected 185 by the available sample sizes, which were very small for some years $\left(N_{y}\right.$; Table 1$)$ and for some maturation cohorts, especially with higher numbers of post-maturation years $\left(n_{p, y}\right)$. Excluded from analyses were any years with $N_{y}<100$ and any combinations of maturation cohort and post-maturation years where $\left(n_{p, y}+n_{p+1, y+1}\right)<20$ or $n_{p, y}<5$. Finally, Beverton et al. (2004) provided evidence that after about 8 spawnings, Norwegian spring-spawning herring suffer increased mortality through senescence; reliable ageing of very old herring is moreover problematic. We therefore excluded any combinations of maturation cohort and 8 or more post-maturation years $\left(n_{p}>7, y\right)$.

\section{Results}

195

Survival and skipped reproduction in male and female herring

Fig. 1a shows the numbers of male and female Norwegian spring-spawning herring sampled in the spawning area for different numbers of post-maturation years. Both sexes show a 
similar pattern of exponentially declining numbers of individuals with increasing postmaturation years, indicating constant annual survival, and under-representation of fish with 1 post-maturation year (second-time spawners), suggesting skipping of the second spawning season by a fraction of potential spawners. Fig. 1b shows proportional change in numbers of male and female spawners between consecutive post-maturation years. The discrepancy in the transitions from $0 \rightarrow 1$ and $1 \rightarrow 2$ post-maturation years, compared with later transitions, suggests that in both sexes the second spawning season may often be skipped.

Applying model (2) to the sexes separately it was found that $46.9 \%$ and $47.3 \%$ of potential female and male second-time spawners, respectively, were missing from the samples and likely skipped reproduction $\left(\mathrm{c}_{I, F}=-0.63, \mathrm{SE}=0.06 ; \mathrm{c}_{I, M}=-0.64, \mathrm{SE}=0.07\right)$. Mean postmaturation survival was estimated at $76 \%$ for females and $71 \%$ for males $\left(\mathrm{c}_{0, F}=-0.27, \mathrm{SE}=\right.$ $0.03 ; \mathrm{c}_{0, M}=-0.34, \mathrm{SE}=0.03$ ). Applying model (4) revealed no significant difference between the sexes either in skipped reproduction $(P=0.300)$ or in post-maturation survival $(P=$ 0.967).

215 Year-class variability in survival and skipped reproduction

For year-classes 1930-70, Fig. 2a shows estimates of annual survival of adult herring, and Fig. $2 \mathrm{~b}$ shows estimated fractions of potential second-time spawners skipping reproduction, based on model (3). Estimates were not available for some of the later year-classes where sample sizes were insufficient, owing to irregular sampling effort (cf. Table 1) and the occurrence of many small year-classes in the second half of the time-series.

Annual survival of spawners was high for all year-classes from 1935-53 (estimates above $60 \%$ in most years; Fig. 2a). In the following year-classes, annual survival dropped substantially to below $30 \%$, reaching a minimum of only $7 \%$ in the 1963 year-class. It is well

225 known that year-classes of the late 1950s and 1960s suffered (very) high fishing mortality, contributing to population collapse in the late 1960s (e.g. Toresen and Østvedt 2000; 
Engelhard and Heino 2004b). Annual survival appeared higher again in year-classes of the latest 1960s, although the estimates are less reliable due to small sample sizes.

Fractions of fish skipping the second spawning season (Fig. 2b) were estimated to be high in the year-classes 1930-34 and $1936(\sim 50-80 \%)$, but low in most year-classes from 1937-53 ( 0-40\%). Estimates were unavailable for those year-classes from 1954-70 that were weak, or for the moderately strong but rapidly fished-out year-class of 1963, owing to small sample sizes. In the strong or moderate year-classes of the later period (1959-61, 1964, 1966), estimated fractions of fish skipping the second spawning season were again fairly high $(\sim 50-60 \%)$.

Length, weight, and condition

Over the year-classes 1930-70 there were generally increasing trends in the mean length, weight, and condition index of spawners (Fig. 3). These were approximately linear for length and weight (Fig. 3a-b), but less so for condition index, which peaked in year-classes 1945-55 (Fig. 3c). In first-time spawners and 'third-time' spawners (strictly, spawners with 2 postmaturation years), trends were significant $(P<0.05)$ for each of the three size variables. In second-time spawners (strictly, spawners with 1 post-maturation year) only the trend in condition index was significant $(P<0.005)$; there was no trend in mean length $(P=0.897)$ while a possible trend in mean weight approached statistical significance $(P=0.090)$.

The mean length, weight, and condition index of first-time spawners had significant effects on the fractions of fish skipping reproduction the year after (Fig. 4a-c, based on equation 4). If first-time spawners had larger body lengths $(P<0.01)$, higher body weights $(P$ $<0.0005)$, or higher condition indices $(P<0.005)$, then skipping of reproduction was less likely to occur in the following year.

Unexpectedly, an inverse relationship of the condition index of spawners in year $y$ with the fraction surviving to year $y+1$ was found $(P<0.005$; Fig. $4 \mathrm{c})$. There were no significant effects of body length $(P=0.743)$ or weight $(P=0.209)$ on survival (Fig. 4a-b). 

spawners with survival and skipped spawning differed significantly between male and female herring.

Environmental variables

Over the period 1935-1974, the annual temperature in the Kola Section of the Barents Sea varied between 2.84 and $4.78{ }^{\circ} \mathrm{C}$, and the North Atlantic Oscillation (NAO) winter index varied between -4.89 and +2.52 (Fig. 5). The NAO index was significantly and positively correlated with the Kola temperature in the same year $(r=0.44, P<0.005)$ as well as in the following year $(r=0.38, P<0.05)$, but not for later or earlier years. The Kola temperature and NAO were characterised by annual fluctuations overlaying long-term (interdecadal) variability (cf. smoothed indices in Fig. 5). Values tended to be high or fairly high from the 1930s through 1950s, but decreased to anomalously low levels in the 1960s and earliest 1970s.

The Kola temperature averaged over year $y$ was negatively correlated with the mean length of first-time spawners at the beginning of year $y+1\left(r_{\mathrm{P}}=-0.48, P<0.01\right.$; Table 2$)$; a negative correlation with first-time spawners' weight approached statistical significance $\left(r_{\mathrm{P}}=\right.$ $-0.36, P=0.060)$, but there was no correlation with condition index $(P=0.878)$. There were no further correlations between the Kola temperature, or NAO winter index, and the mean length, weight or condition of spawners at the beginning of year $y+1$. Neither were there any lagged correlations with these indices at the beginning of year $y+2$ (Table 2).

Using general linear models, we examined how the Kola temperature, NAO winter index, and condition of herring may be related to adult survival and the fraction of fish skipping the second spawning season (see Table 3 for a selection of models). There was strong evidence that the Kola temperature in year $y$ was significantly but inversely related with both survival and participation in the second spawning season (Table 3: Model K1, confirmed by Models K2 and C2; note sharp decreases in AIC compared to the null model). 
This suggested that colder temperatures lead to better adult survival and less frequent skipping of spawning. Moreover, a lagged relationship between the Kola temperature and skipped spawning, but not survival, after 2 years was found, again suggesting that colder temperatures lead to a decrease in skipped spawning (Model K2). These direct and lagged relationships were also found if Model K2 was extended to include herring condition (Model C2; significant drop in AIC by 4.4).

Evidence of relationships of the NAO with adult herring survival and skipped spawning was comparatively weak and not fully conclusive. Models including the NAO only (Model N1) or extended to include also a lagged NAO effect (Model N2) had higher AIC values compared to the null model, and did not reveal signicant relationships. However, several models that also included the Kola temperature (e.g. Model C3, 'best model' with lowest AIC) did suggest relationships of the NAO with skipped spawning, although interpretation requires caution given the close correlation between the two environmental variables. In all models examined, the Kola temperature was more tightly related with both survival and skipped spawning than the NAO.

\section{Discussion}

This study provides improved understanding why a significant fraction of adult Norwegian spring-spawning herring may not spawn strictly annually, but instead skip the second reproductive season (Engelhard and Heino 2005). First, it describes long-term changes in the frequency of skipped reproduction. Second, it shows that the size and condition of first-time spawners, as well as environmental variables, are linked with the extent to which these fish skip reproduction the year after, although there are no differences between the sexes. Third, relationships are revealed between condition, environmental variables, and survival of adult herring.

There are two caveats in interpreting our results. First, these are based on indirect evidence of skipped reproduction-under-representation of second-time spawners. Direct 
evidence of skipped reproduction in Atlantic herring is still lacking. An alternative hypothesis to explain the data is that lack of second-time spawners is due to frequent scale-reading errors. However, the ring widths in scales appear consistent between individuals that matured at the same age but were sampled in different years following maturation (Engelhard and Heino 2005). While we maintain that skipped reproduction is the most parsimonious explanation for the observed patterns, the possibility of scale-reading errors producing artifactual patterns cannot be fully discounted (see Engelhard and Heino 2005 for discussion).

Second, we observe skipped reproduction only probabilistically at the aggregate level of maturation cohorts. Therefore, for further analyses, individual-level biological data (fish size and condition) need to be aggregated to the corresponding degree; environmental data are only available at yearly resolution from the onset. It is not to be taken for granted that aggregated data accurately reflect individual-level processes affecting skipped reproduction. Furthermore, our perception on the dynamics of these maturation cohorts, and frequency of skipped reproduction, is influenced by the input from the stock assessment (ICES 2002): estimated stock numbers, and for some analyses fishing mortality. Such errors are expected to add noise to the estimates of skipped reproduction, but not bias. Survival, however, is overestimated if for some period stock assessment suggests a trend in stock numbers that is shallower than in reality, and vice versa.

The absence of sex differences in skipped reproduction is in line with previous work 330 showing no sex differences in age or size at maturation (Engelhard et al. 2003) or body fat content (Slotte 1999a) in this stock, suggesting similar reproductive investment in males and females. The similarities may well relate to the collective behaviour in herring schools (Fernö et al. 1998; Axelsen et al. 2000), which typically consist of about equal numbers of both sexes; individuals are, in 'deciding' whether to participate in spawning migration, strongly dependent on the decisions of surrounding individuals (Huse et al. 2002).

Overall, the results corroborate well with life-history theory predicting that adult individuals are expected to skip reproduction when the loss in fecundity this season is more than balanced by increased fecundity in the future, discounted by the survival probability up 
to that point (Roff 2002). Investment in reproductive activity implies costs and risks, such as reduction in growth and survival and hence expected future reproductive success (Stearns 1992). In Norwegian spring-spawning herring, a high cost of reproduction is evidenced by a strong decrease in growth rate after maturation (Runnström 1936; Engelhard et al. 2003). Trade-offs between current and future reproduction, growth and survival imply that participation in spawning will only pay off in terms of fitness when herring are sufficiently large and in sufficiently good condition. Indeed, this study shows that mean length, weight and condition in cohorts of first-time spawners are significantly and positively related with participation in spawning the year after (Fig. $4 \mathrm{a}-\mathrm{c}$ ). Thus, strong support is provided for the hypothesis (Engelhard and Heino 2005) that young adult herring, which owing to small size rely heavily on condition, after first reproduction often need an extra year to re-gain the energy stores required for reproduction, in contrast to older adult herring which are advantaged by larger size (compare with Fig. 3). Correspondingly, inverse relationships between condition and the likelihood of skipped reproduction have also been found for several other species (fish: Rijnsdorp 1990, Oganesyan 1993, Burton et al. 1997, Rideout et al. 2000; reptiles: Broderick et al. 2003).

It is not surprising that first-time spawning herring are more likely to skip an entire reproductive season when of smaller size and/or in reduced condition. The extensive spawning migrations incur a high energetic cost even before actual spawning can be commenced; since herring do not feed while migrating, only fish with sufficient energy stores can successfully migrate and spawn (e.g. Slotte and Fiksen 2000). Moreover, smaller fish have an additional disadvantage due to the positive relationship of fish length with swimming speed (Ware 1978). Finally, predation risk is likely to be particularly high for spawning herring; they are preyed upon by a range of coastal predators including fishes, marine mammals, and seabirds (Fernö et al. 1998; Høines and Bergstad 1999; Axelsen et al. 2000). Under the given conditions, skipping the second season, rather than exacerbating already low 365 energy stores, is likely to be an optimal life-history strategy leading to improved lifetime reproductive success (cf. Jørgensen et al. 2006). 
The inverse relationship between condition and survival was opposite to the expected (Fig. 4c). This may be due to errors in relative stock numbers that confound the survival estimates. However, this relationship may also be real. If so, reduced condition and increased survival may not have cause-effect relationships, but rather be the result of common underlying causes. First, favourable conditions early in life can result in high survival but reduced growth and condition due to reduced per capita food intake, as a density-dependent effect (Barros and Toresen 1998). Second, strong year-classes, characterised by reduced growth and condition indices (Toresen 1990; Holst 1996) may suffer less predation and exploitation mortality due to the dilution effect (Axelsen et al. 2001). Alternatively, if skipped reproduction is not restricted to the second spawning season but also occurs in older spawners, then the inverse relationship between condition and survival might even be the result of skipped reproduction per se. In strict sense, survival estimates presented here indicate annual changes in fish numbers present in the spawning area. In a year of low body condition, all adult herring might have a tendency to skip reproduction and thus be underrepresented in the spawning area: if the same fish return to spawn the year after, this will lead to an inverse condition-survival relationship in data collected from the spawning area. Unfortunately, if skipping of reproduction becomes unsynchronised after the second spawning season, it becomes particularly hard to study with the data available to us, as it is not possible to separate absence of spawners due to skipping from absence due to mortality (Engelhard and Heino 2005).

The extent to which herring may skip reproduction was found to be not only related to fish size and condition but also to climatic factors. The mean temperature in the Kola section of the Barents Sea for a given year was inversely related to adult survival, and to participation in the second spawning season in the following two years (Table 3). Relationships with the North Atlantic Oscillation were less clear but cannot be excluded given the close correlation between the two environmental variables; by and large, there appeared to be a tighter link with the Kola temperature than with the NAO. Notably, colder temperatures, possibly associated with a negative NAO index, favoured both adult survival and participation 
in the second spawning season (Table 3). Prey availability is a possible mechanism for this. The copepod Calanus finmarchicus, a key species in the Norwegian Sea ecosystem, is the most important prey species for adult herring during the summer-feeding season (Dalpadado et al. 2000). There is an inverse relationship of $C$. finmarchicus abundance with the NAO and sea surface temperatures (Fromentin and Planque 1996).

In contrast, the Kola temperature is also positively associated with overall stock abundance of Norwegian spring-spawning herring, through a positive effect on year-class strength (Toresen and Østvedt 2000). The prime nursery areas for this stock, however, are in the Barents Sea, which is widely distant from the feeding areas for adult herring in the Norwegian Sea. In the Barents Sea, Calanus abundance is thought to be positively related to the Kola temperature, as warmer temperatures are associated with increased influx of copepod-rich waters from the Atlantic (Aksnes and Blindheim 1996). The possibility of contrasting climate effects on juvenile and adult herring has interesting population implications. Usually, variations in survival early in life far exceed those in adults, so that the relationship of overall stock abundance with temperature will still follow that of juveniles (in agreement with Toresen and Østvedt 2000). In spite of that, the inverse temperature effect on adult herring survival and skipped reproduction remains relevant as it is directly linked to the population's reproductive potential, and refers to the part of the stock relevant to commercial fisheries.

In conclusion, interannual variability in the Norwegian Sea environment and 415 variations in the size and condition of spawning herring (Figs. 4, 6) may explain the dynamics in frequency of skipped reproduction in Norwegian spring-spawning herring (Fig. 2). The decrease in frequency of skipped reproduction in year-classes from the 1930s-1950s may have resulted from a gradual increase in herring condition (Holst 1996), combined with particularly warm temperatures in the beginning of the time-series (Fig. 5). High frequency of skipped reproduction in year-classes 1959-1961 was likely related to particularly low weight and condition (Fig. 3). When the stock was at extremely low levels in the two decades following stock collapse in the late 1960s, growth and condition indices were particularly 
high (Toresen 1990, Engelhard and Heino 2004a); we may postulate that infrequent skipping of reproduction contributed to stock recovery. On the other hand, a year of poor environmental conditions, by affecting growth and condition, can have a threefold negative effect on reproductive potential: (1) by increasing mortality, (2) by reducing the mean fecundity per individual spawner (Marshall et al. 1998; Blanchard et al. 2003), and (3) by increasing the fraction of adults skipping reproduction. The very strong annual fluctuations in year-class strength in Norwegian spring-spawning herring (ICES 2002) may thus partly, among other factors, be explained by variations in skipped spawning. The major implications of skipped reproduction for population dynamics and reproductive potential highlight the need for critical re-evaluation of a common presumption in fish stock assessments—-that adult fish spawn strictly annually.

Acknowledgements This study was supported by the Department for Environment, Food \& Rural Affairs of the United Kingdom (Contract MFO322) and by the European Research Training Network ModLife, funded through the Human Potential Programme of the European Commission (Contract HPRN-CT-2000-00051). Ewen Bell, Georgi Daskalov, Christian Jørgensen, Robert Scott, and Reidar Toresen provided valuable discussions.

\section{References}

Aksnes DL, Blindheim J (1996) Circulation patterns in the North Atlantic and possible impact on population dynamics of Calanus finmarchicus. Ophelia 44:7-28.

445 Axelsen BE, Nøttestad L, Fernö A, Johannesen A, Misund OA (2000) 'Await' in the pelagic: dynamic trade-off between reproduction and survival within a herring school splitting vertically during spawning. Mar Ecol Prog Ser 205:250-269.

Axelsen BE, Anker-Nilssen T, Fossum P, Kvamme C, Nøttestad L (2001) Pretty patterns but a simple strategy: predator-prey interactions between juvenile herring and Atlantic puffins observed with multibeam sonar. Can J Zool 79:1586-1596. 
Barros P, Toresen R (1998) Variable natural mortality rate of juvenile Norwegian springspawning herring (Clupea harengus) in the Barents Sea. ICES J Mar Sci 55:430-442.

Beverton RJH, Hylen A, Østvedt OJ, Alvsvaag J, Iles TC (2004) Growth, maturation, and longevity of maturation cohorts of Norwegian spring-spawning herring. ICES J Mar 455 Sci 61:165-175.

Blanchard JL, Frank KT, Simon JE (2003) Effects of condition on fecundity and total egg production of eastern Scotian Shelf haddock (Melanogrammus aeglefinus). Can J Fish Aquat Sci 60:321-332.

Bochkov YA (1982) Water temperature in the 0-200 m depth layer in the "Kola Meridian" in the Barents Sea, 1900-1981. Sb Nauch Trud PINRO 46:113-122. (In Russian).

Broderick AC, Glen F, Godley BJ, Hays GC (2003) Variation in reproductive output of marine turtles. J Exp Mar Biol Ecol 288:95-109.

Burton MPM, Penney RM, Biddiscombe S (1997) Time course of gametogenesis in Northwest Atlantic cod (Gadus morhua). Can J Fish Aquat Sci 54 (Suppl 1):122-131.

465 Dalpadado P, Ellertsen B, Melle W, Dommasnes A (2000) Food and feeding conditions of Norwegian spring-spawning herring (Clupea harengus) through its feeding migrations. ICES J Mar Sci 57:843-857.

Engelhard GH, Dieckmann U, Godø OR (2003) Age at maturation predicted from routine scale measurements in Norwegian spring-spawning herring (Clupea harengus) using discriminant and neural network analyses. ICES J Mar Sci 60:304-313.

Engelhard GH, Heino M (2004a) Maturity changes in Norwegian spring-spawning herring before, during, and after a major population collapse. Fish Res 66:299-310.

Engelhard GH, Heino M (2004b) Maturity changes in Norwegian spring-spawning herring Clupea harengus: compensatory or evolutionary responses? Mar Ecol Prog Ser 272:245-256.

Engelhard GH, Heino M (2005) Scale analysis suggests frequent skipping of the second reproductive season in Atlantic herring. Biol Lett 1:172-175. 
Fernö A, Pitcher TJ, Melle W, Nøttestad L, Mackinson S, Hollingworth C, Misund OA (1998) The challenge of the herring in the Norwegian Sea: making optimal spatial decisions. Sarsia 83:149-167.

Fiksen Ø, MacKenzie BR (2001) Optimal state-dependent allocation to growth or reproduction in cod. ICES CM 2001/V:12.

Fromentin J-M, Planque B (1996) Calanus and environment in the eastern North Atlantic. II. Influence of the North Atlantic Oscillation on C. finmarchicus and C. helgolandicus. Mar Ecol Prog Ser 134:111-118.

Holst JC (1996) Long term trends in the growth and recruitment pattern of the Norwegian spring-spawning herring (Clupea harengus Linnaeus 1758). PhD Dissertation, University of Bergen, Norway.

Huse G, Railsback S, Fernö A (2002) Modelling changes in migration patterns of herring: collective behaviour and numerical domination. J Fish Biol 60:571-582.

Høines ÅS, Bergstad OA (1999) Resource sharing among cod, haddock, saithe and pollack on a herring spawning ground. J Fish Biol 55:1233-1257.

ICES (2002) Report of the Northern Pelagic and Blue Whiting Fisheries Working Group, Vigo, Spain, 29 April-8 May 2002. ICES CM 2002/ACFM:19.

Jørgensen C, Ernande B, Fiksen Ø, Dieckmann U (2006) The logic of skipped spawning in fish. Can J Fish Aquat Sci 63 :200-211.

Marshall CT, Kjesbu OS, Yaragina NA, Solemdal P, Ulltang Ø (1998) Is spawner biomass a sensitive measure of the reproductive and recruitment potential of Northeast Arctic cod? Can J Fish Aquat Sci 55:1766-1783.

Oganesyan SA (1993) Periodicity of the Barents Sea cod reproduction. ICES CM 1993/G:64.

Rideout RM, Burton MPM, Rose GA (2000) Observations on mass atresia and skipped spawning in northern Atlantic cod, from Smith Sound, Newfoundland. J Fish Biol 57:1429-1440.

Rideout RM, Rose GA, Burton MPM (2005) Skipped spawning in female iteroparous fishes. Fish Fisheries 6:50-72. 
Rijnsdorp AD (1990) The mechanism of energy allocation over reproduction and somatic growth in female North Sea plaice, Pleuronectes platessa L. Neth J Sea Res 25:279290.

Roff DA (2002) Life History Evolution. Sinauer Ass., Sunderland, Massachusetts.

Runnström S (1936) A study on the life history and migrations of the Norwegian springherring based on the analysis of the winter rings and summer zones of the scale. FiskDir Skr Ser HavUnders 5 (2):1-103.

Slotte A (1999a) Differential utilization of energy during wintering and spawning migration in Norwegian spring-spawning herring. J Fish Biol 54:338-355.

515 Slotte A (1999b) Effects of fish length and condition on spawning migration in Norwegian spring-spawning herring (Clupea harengus L.). Sarsia 84:111-127.

Slotte A, Fiksen $\varnothing$ (2000) State-dependent spawning migration in Norwegian springspawning herring. J Fish Biol 56:138-162.

Stearns SC (1992) The Evolution of Life Histories. Oxford University Press, New York.

Toresen R (1990) Long-term changes in growth of Norwegian spring-spawning herring. J Cons Int Explor Mer 47:48-56.

Toresen R, Jakobsson J (2002) Exploitation and management of Norwegian spring-spawning herring in the 20th century. ICES Mar Sci Symp 215:558-571.

Toresen R, Østvedt OJ (2000) Variation in abundance of Norwegian spring-spawning herring (Clupea harengus, Clupeidae) throughout the 20th century and the influence of climatic fluctuations. Fish Fisheries 1:231-256.

Ware DM (1978) Bioenergetics of pelagic fish: theoretical change in swimming speed and ration with body size. J Fish Res Board Can 35:220-228. 
Fig. 1a Numbers of male and female herring, sampled in the spawning area during the spawning seasons of 1935-1973, at different numbers of post-maturation years. First-time spawners have 0 postmaturation years. Note strong under-representation of second-time spawners (1 post-maturation year). b Proportional change (with SE) in numbers of male and female herring, present in the spawning area, from $p$ to $p+1$ post-maturation years (estimated with model 1 ).
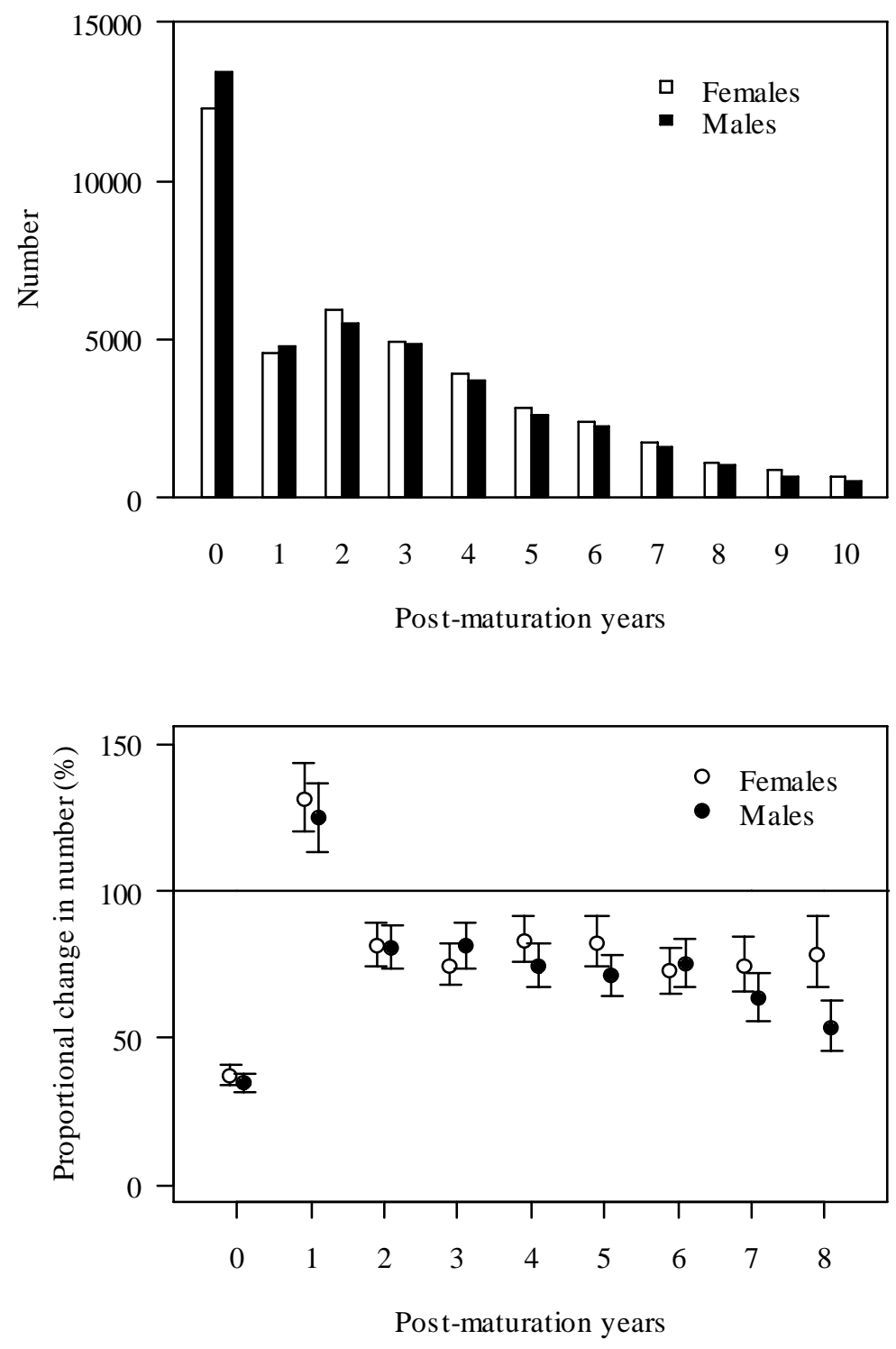
Fig. 2 Year-class variability in (a) estimated annual survival (with SE) of adult herring, and (b) the estimated fraction (with SE) of potential second-time spawners skipping reproduction, derived from equation (3). Survival estimates are potentially confounded by errors in the stock-assessment based estimates of annual changes in stock numbers. Estimates were not available for some year-classes where sample sizes were insufficient.
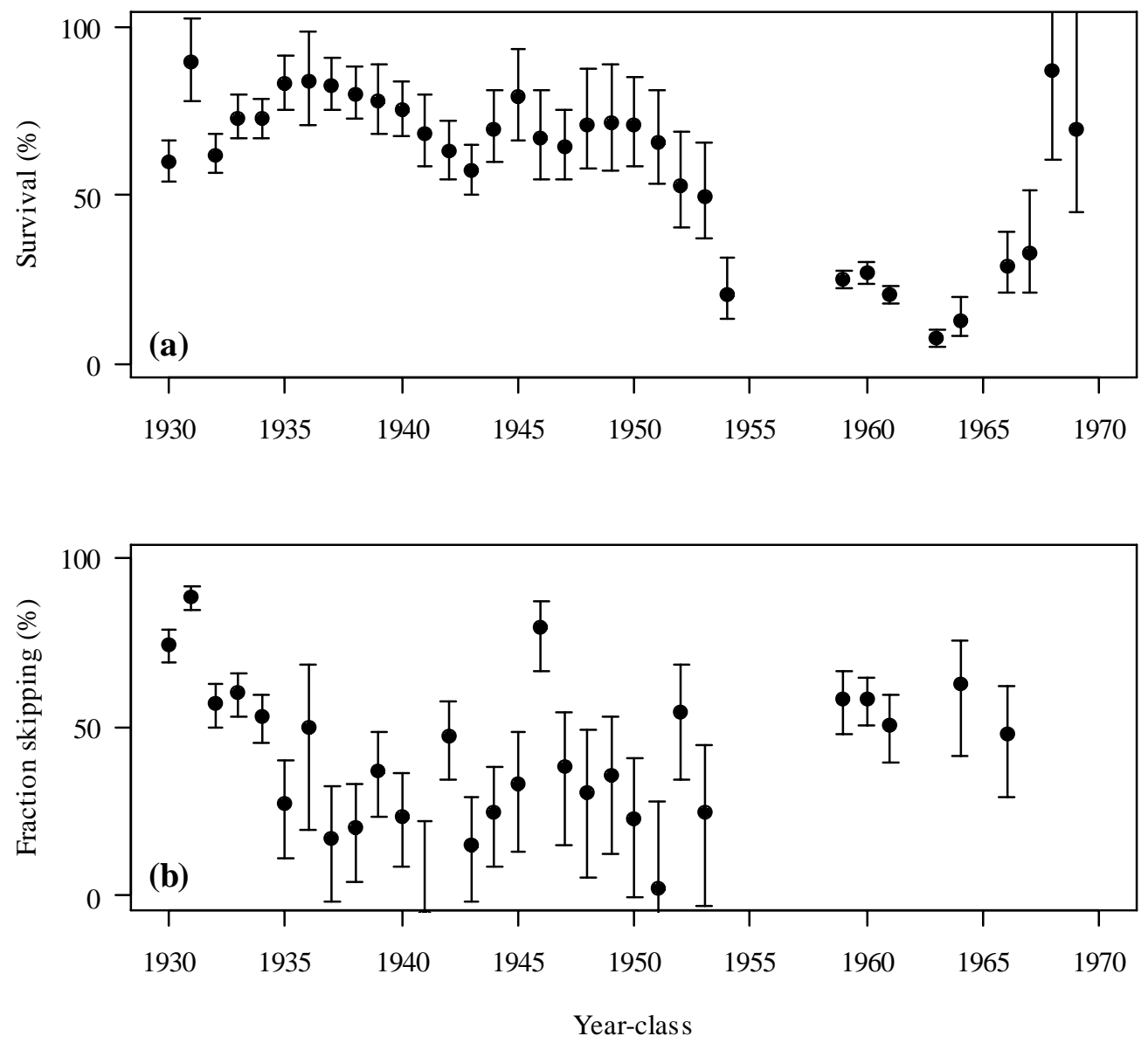
545 Fig. 3 Year-class variability for 1930-1970 in (a) mean length, (b) weight, and (c) condition index for first-time spawners (black symbols), second-time spawners (grey), and third-time spawners (white; strictly, spawners with 2 post-maturation years). Note that the figures only include fish indeed present in the spawning areas. Symbols show the grand means (with SE) of the means for maturation cohortsat-age. Solid, hatched and dotted lines indicate temporal trends for first-time, second-time and thirdtime spawners, respectively.
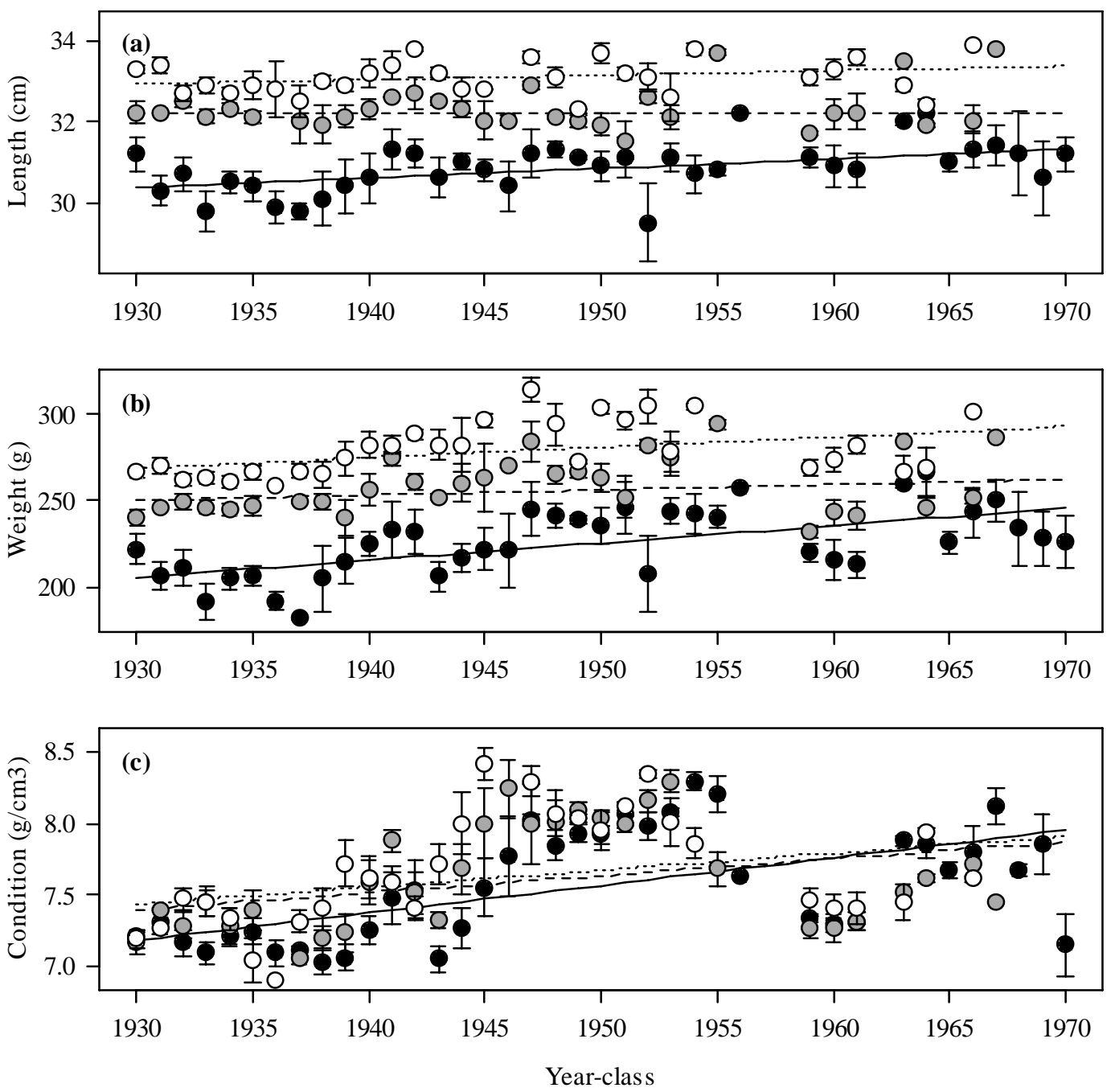
Fig. 4 Symbols: Relationships between the mean length (a), weight (b), and condition index (c) of maturation cohorts as first-time spawners in year $y$, and the estimated fraction of fish skipping reproduction in year $y+1$ (equation 4 but size variables analysed as factors). Vertical bars indicate SE of estimates; numbers indicate sample sizes (i.e., number of maturation cohorts by sex in each size bin). Dotted lines: modelled relationships between length, weight, and condition of first-time spawners and the fraction of fish skipping reproduction the year after (equation 4; size variables analysed as variates). Solid lines: overall survival from year $y$ to year $y+1$ as a function of length, weight, and condition in year $y$, as modelled for all spawners (both first-time and repeat spawners, excluding second-time spawners). Analysis excludes data from 1966-73 (period of extremely high fishing mortality and resulting stock collapse).
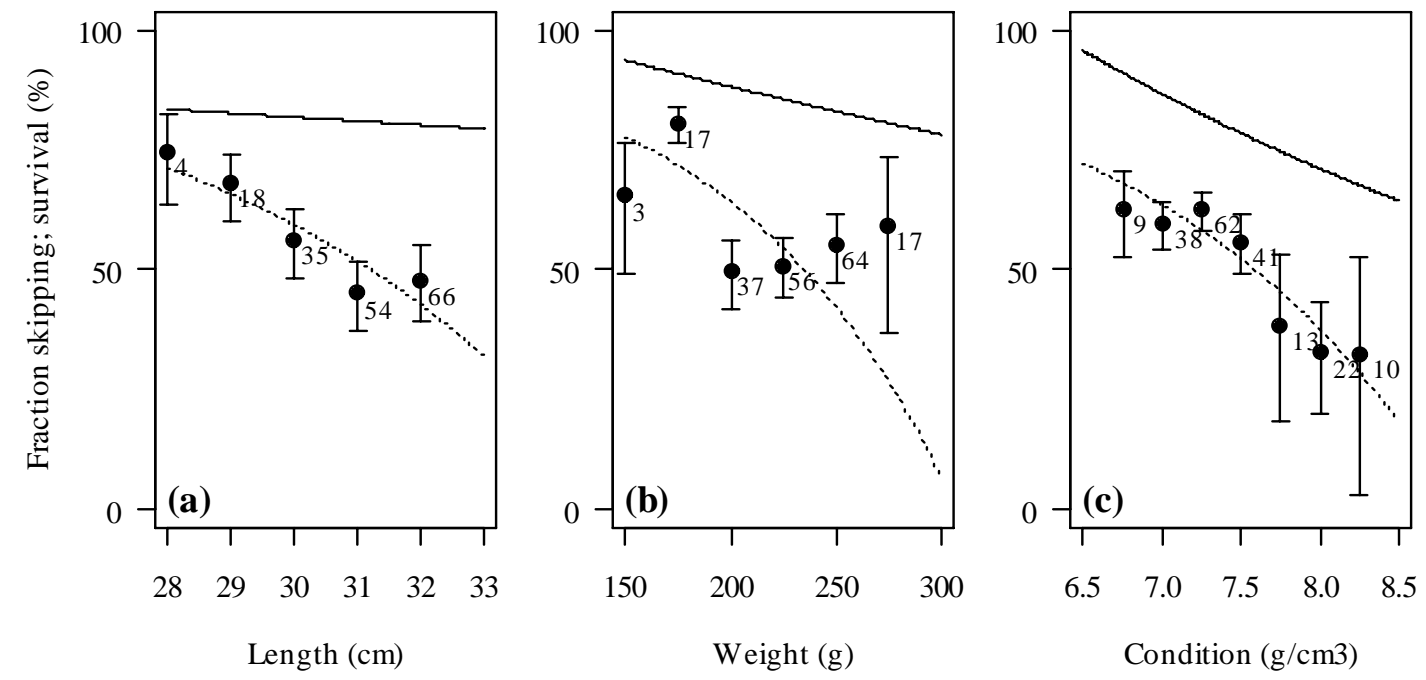

565 
Fig. 5 Interannual variability for 1935-1974 in (a) the mean annual temperature in the Kola Section of the Barents Sea and (b) the NAO winter index. The heavy solid lines represent values smoothed with a low-pass filter with 7 weights $(1,3,5,6,5,3$ and 1) to remove fluctuations with periods less than 4 years.
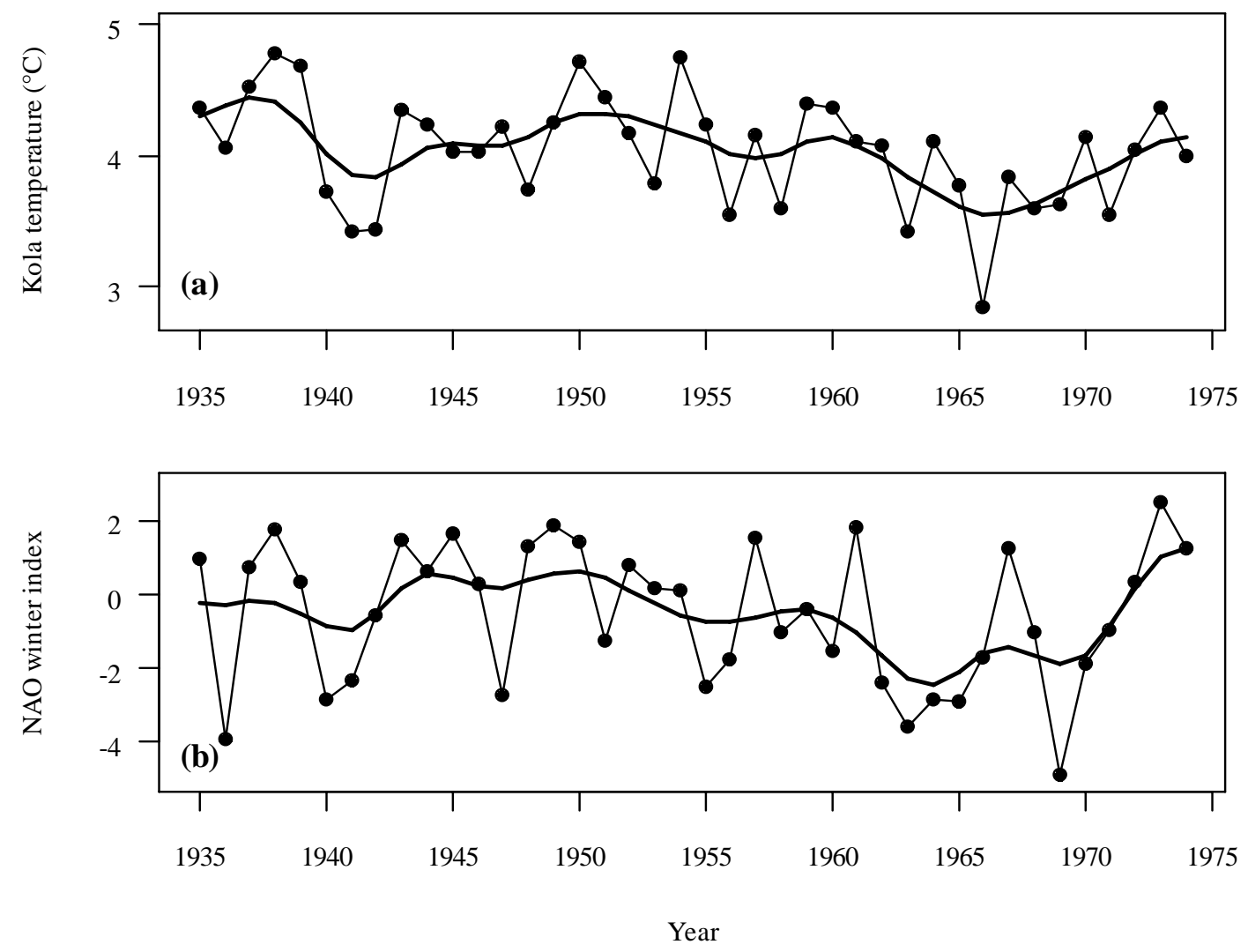
Table 1 Total annual numbers of observations $\left(N_{y}\right)$ on age at maturation and post-maturation years in Norwegian spring-spawning herring, collected in the spawning areas by the Institute of Marine Research, 1935-1973. Note that analyses on skipped reproductive seasons require decent sample sizes in at least two consecutive years. Years where $N_{y}<100$ were excluded from analyses.

580

\begin{tabular}{rrrrrr}
\hline Year & $N_{y}$ & Year & $N_{y}$ & Year & $N_{y}$ \\
\hline 1935 & 2578 & 1948 & 2584 & 1961 & 2048 \\
1936 & 2818 & 1949 & 3281 & 1962 & 9 \\
1937 & 2568 & 1950 & 3257 & 1963 & 3 \\
1938 & 1974 & 1951 & 4337 & 1964 & 13 \\
1939 & 1681 & 1952 & 0 & 1965 & 1999 \\
1940 & 5641 & 1953 & 0 & 1966 & 2270 \\
1941 & 3881 & 1954 & 4258 & 1967 & 2271 \\
1942 & 159 & 1955 & 5161 & 1968 & 1946 \\
1943 & 1852 & 1956 & 44 & 1969 & 1898 \\
1944 & 2423 & 1957 & 51 & 1970 & 1 \\
1945 & 2322 & 1958 & 5154 & 1971 & 2438 \\
1946 & 4681 & 1959 & 3841 & 1972 & 419 \\
1947 & 3889 & 1960 & 8 & 1973 & 357 \\
\hline
\end{tabular}


Table 2 Pearson correlation coefficients between environmental variables (Kola temperature and NAO winter index) and the mean length $(\mathrm{cm})$, weight $(\mathrm{g})$ and condition $\left(\mathrm{g} \mathrm{cm}^{-3}\right)$ for first-, second- and thirdtime spawners (strictly, spawners with 0,1 and 2 post-maturation years, respectively) sampled the winter immediately after and with a delay of 1 year. ** denotes correlation significant at the 0.01 level.

\begin{tabular}{|c|c|c|c|c|}
\hline & \multicolumn{2}{|c|}{ Kola temperature $\left({ }^{\circ} \mathrm{C}\right)$} & \multicolumn{2}{|c|}{ NAO winter index } \\
\hline & Year $y+1$ & Year $y+2$ & Year $y+1$ & Year $y+2$ \\
\hline \multicolumn{5}{|c|}{ First-time spawners } \\
\hline Length & $-0.48 * *$ & 0.14 & -0.27 & 0.03 \\
\hline Weight & -0.36 & 0.04 & -0.03 & 0.13 \\
\hline Condition & -0.03 & 0.13 & 0.18 & 0.15 \\
\hline \multicolumn{5}{|c|}{ Second-time spawners } \\
\hline Length & -0.28 & 0.13 & -0.16 & 0.14 \\
\hline Weight & -0.08 & 0.09 & 0.08 & 0.33 \\
\hline Condition & 0.16 & 0.04 & 0.21 & 0.27 \\
\hline \multicolumn{5}{|c|}{ Third-time spawners } \\
\hline Length & -0.22 & 0.20 & -0.13 & 0.24 \\
\hline Weight & -0.10 & 0.10 & 0.04 & 0.27 \\
\hline Condition & 0.05 & 0.00 & 0.11 & 0.10 \\
\hline
\end{tabular}


Table 3 Summary of selected general linear models examining effects of the Kola temperature $\left({ }^{\circ} \mathrm{C}\right)$, NAO winter index, and condition of herring $\left(\mathrm{g} \mathrm{cm}^{-3}\right)$ in year $y$ on survival from year $y \rightarrow y+1$ and on the fraction of fish skipping the second spawning season in year $y+1$. Bold type indicates coefficients 590 (shown with SE) significantly different from zero $(P<0.05)$. Note that a positive coefficient implies that a variable is positively related with either survival (see left columns) or participation in the second spawning season (right); the latter is equivalent to fewer fish skipping reproduction. Models K1-2 (including Kola temperature), N1-2 (including NAO) and C1-3 (including both herring condition and environmental variables) were selected based on biological significance and the Akaike information

595 criterion (AIC). Delta $\operatorname{AIC}\left(\Delta_{i}\right)$ and Akaike weights $\left(w_{i}\right)$ are shown as a measure of the strength of each model relative to the 'best' model (i.e., Model C3).

\begin{tabular}{|c|c|c|c|c|c|c|c|c|c|c|}
\hline \multirow[t]{2}{*}{ Model } & \multirow[t]{2}{*}{ Variable } & \multicolumn{3}{|c|}{ Survival } & \multicolumn{3}{|c|}{ Participation 2nd spawning } & \multirow[t]{2}{*}{$\mathrm{AIC}$} & \multirow[t]{2}{*}{$\Delta_{i}$} & \multirow[t]{2}{*}{$w_{i}$} \\
\hline & & Coefficient & $\mathrm{SE}$ & $P$ & Coefficient & SE & $P$ & & & \\
\hline Null model & $\begin{array}{l}\text { Excludes condition or } \\
\text { environmental variables }\end{array}$ & & & & & & & 1025.0 & 80.1 & 0 \\
\hline Model K1 & Kola temperature, year $y$ & -0.331 & 0.073 & $<0.0001$ & -0.425 & 0.152 & $<0.01$ & 978.5 & 33.6 & 0 \\
\hline \multirow[t]{2}{*}{ Model K2 } & Kola temperature, year $y$ & -0.333 & 0.072 & $<0.0001$ & -0.395 & 0.149 & $<0.01$ & 956.6 & 11.7 & 0.003 \\
\hline & Kola temperature, year $y$-1 & -0.021 & 0.090 & 0.815 & -0.746 & 0.175 & $<0.0001$ & & & \\
\hline Model N1 & NAO, year $y$ & -0.022 & 0.017 & 0.187 & 0.035 & 0.035 & 0.321 & 1027.1 & 82.2 & 0 \\
\hline \multirow[t]{2}{*}{ Model N2 } & NAO, year $y$ & -0.021 & 0.017 & 0.215 & 0.041 & 0.035 & 0.247 & 1025.6 & 80.7 & 0 \\
\hline & NAO, year $y-1$ & -0.024 & 0.020 & 0.234 & -0.042 & 0.038 & 0.275 & & & \\
\hline Model C1 & Condition, year $y$ & -0.198 & 0.065 & $<0.005$ & 0.538 & 0.169 & $<0.005$ & 1015.1 & 70.2 & 0 \\
\hline \multirow[t]{3}{*}{ Model C2 } & Condition, year $y$ & -0.172 & 0.062 & $<0.01$ & 0.294 & 0.162 & 0.070 & 952.2 & 7.3 & 0.025 \\
\hline & Kola temperature, year $y$ & -0.312 & 0.072 & $<0.0001$ & -0.405 & 0.149 & $<0.01$ & & & \\
\hline & Kola temperature, year $y$-1 & -0.061 & 0.091 & 0.504 & -0.686 & 0.176 & $<0.0005$ & & & \\
\hline \multirow{4}{*}{$\begin{array}{c}\text { Model C3 } \\
\text { (final } \\
\text { model) }\end{array}$} & Condition, year $y$ & -0.196 & 0.069 & $<0.005$ & 0.446 & 0.168 & $<0.01$ & 944.9 & 0.0 & 0.972 \\
\hline & Kola temperature, year $y$ & -0.281 & 0.082 & $<0.001$ & -0.739 & 0.179 & $<0.0001$ & & & \\
\hline & Kola temperature, year $y$-1 & -0.083 & 0.095 & 0.382 & -0.467 & 0.187 & $<0.05$ & & & \\
\hline & NAO, year $y$ & -0.015 & 0.020 & 0.449 & 0.138 & 0.043 & $<0.005$ & & & \\
\hline
\end{tabular}

